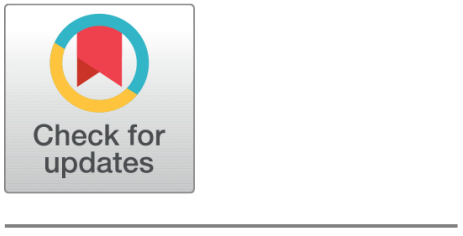

OPEn ACCESS

Received: 08.02.2021

Accepted: 16.03 .2021

Published: 10.04.2021

Citation: Susanth SG (2021) A brief review on the

Atmosphere-lonosphere coupling during Stratospheric sudden warming over the tropical region. Indian Journal of Science and Technology 14(11): 956-963. https:// doi.org/10.17485/IJST/V14i11.251

* Corresponding author.

Tel: +919746445455

sgsusanthsg@gmail.com

Funding: None

Competing Interests: None

Copyright: (c) 2021 Susanth. This is an open access article distributed under the terms of the Creative Commons Attribution License, which permits unrestricted use, distribution, and reproduction in any medium, provided the original author and source are credited.

Published By Indian Society for Education and Environment (iSee)

ISSN

Print: 0974-6846

Electronic: 0974-5645

\section{A brief review on the Atmosphere-Ionosphere coupling during Stratospheric sudden warming over the tropical region}

\author{
S G Susanth ${ }^{1 *}$ \\ 1 Department of Applied Science and Humanities, Lourdes Matha College of Science and \\ Technology, Trivandrum, 695574, India. Tel.: +91 9746445455
}

\begin{abstract}
Objective: A brief review on the effects of Sudden Stratospheric Warming (SSW) over the equatorial upper atmosphere (80-500 km) obtained using both ground and space based measurements are presented. The emphasis is given to understand the role of semi-diurnal tidal activity during the SSW. Methods: In order to address this aspect, zonal wind data obtained using meteor wind radar over a tropical station; Trivandrum in India $\left(8.5^{\circ} \mathrm{N}, 77.0^{\circ} \mathrm{E}\right)$ has been used. Wavelet analysis has been carried out to investigate the role of semi-diurnal and terdiurnal tides during the SSW event of January 2008. For characterizing the event, polar stratospheric temperature (PST) at $10 \mathrm{hPa}$, as obtained using National Centers for Environmental Prediction (NCEP) and the National Center for Atmospheric Research (NCAR) reanalysis data has been used. In order to characterize the normal behavior, the aforementioned database during December 2007 has been also looked into. Findings: It has been understood that the tropical upper atmosphere exhibits substantial changes in connection with SSW with an increase in the amplitudes of semi diurnal tides of the order of $10-15 \mathrm{~m} / \mathrm{s}$ in comparison with the normal period. Over the equatorial ionosphere, the changes were observed right from the $\mathrm{E}$ region, extending upto the topside F region. It was noticed that the imprints of SSW were not only restricted to the neutral atmospheric parameters such as temperature, density, wind, but also found to have distinct signatures in the electrodynamic processes such as Equatorial electrojet (EEJ), Equatorial Ionization Anomaly (EIA), Equatorial Spread-F (ESF) as well. Novelty: The study, probably for the first time, has conclusively shown that it is not the terdiurnal tides, but the semi-diurnal tides, which are responsible for the SSW induced effects due to its non-linear interaction with planetary waves.
\end{abstract}

Keywords: Stratospheric sudden warming; Equatorial ionosphere; waves and tides 


\section{Introduction}

Sudden Stratospheric Warming (SSW) is a dramatic and large scale meteorological phenomenon in the winter polar stratosphere caused by the rapid growth of Quasi Stationary Planetary Waves (QSPW) and their interaction with the stratospheric mean circulation $^{(1)}$. During SSW, the polar stratospheric temperature (PST) increases abruptly by even up to $\sim 60 \mathrm{~K}$ and the zonal mean zonal winds change its direction (from eastward to westward) due to the breaking up of polar vortex. It is widely accepted that SSW results from the non-linear interaction between the QSPW and the zonal mean flow, which inturn slows down or reverses the stratospheric winter jet. The associated Coriolis force strengthens the poleward Brewer-Dobson circulation. Subsequent enhancement in the downwelling of polar region resulting in the increased adiabatic warming is believed to be the main causative mechanism for the increase in stratospheric temperature. The resonant growth of planetary waves ${ }^{(2)}$ and resonant enhancement of a barotropic mode of the polar vortex ${ }^{(3)}$ are suggested to be the main reasons for the rapid growth of planetary waves, still, the complete explanation is yet to evolve. Accompanying these changes, the stratopause descends over some locations by as much as $20 \mathrm{~km}$.

Although, the SSW and its effects were initially believed to have signatures over the polar latitude, it was realized that it can have significant implications in the understanding of energetics and dynamics of the middle and tropical upper atmosphere. Over other latitudes, the changes were noticed not only over the troposphere and stratosphere, but also over the mesosphere and thermosphere altitudes. Recently, the role of SSW over the low/equatorial ionosphere has also been gleaned out ${ }^{(4)}$. In this context, an attempt is made here to explore the important scientific results concerning the SSW and its effects over the other altitudes/latitudes. The emphasis is given to understand the role of SSW over equatorial/low latitude upper atmosphere in the context of neutral and electrodynamical coupling processes prevalent therein. As an example, the case of 2008 SSW event has been investigated here in context of the tidal amplitudes as obtained using the meteor wind radar over the tropical station, Trivandrum $\left(8.8^{0} \mathrm{~N}, 77^{0} \mathrm{E}\right)$ in India.

\section{Atmospheric effects during SSW}

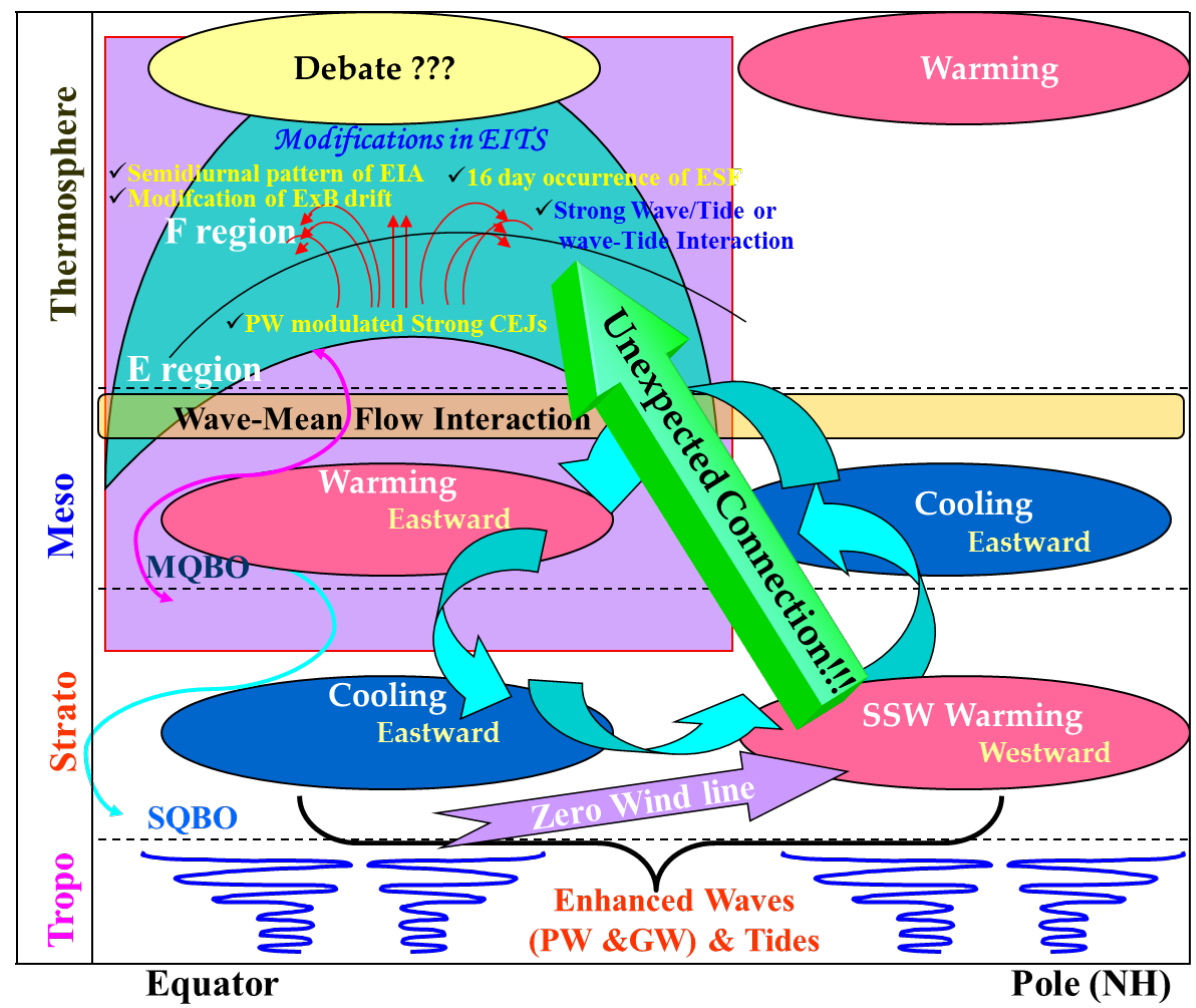

Fig 1. The schematic showing the global impacts of SSW highlighting the changes in circulation, energetics and its role in the high latitude-low latitude coupling. 
Studies have shown that SSW events have a strong impact globally influencing the background wind, temperature, chemistry and wave activity of the lower, middle and upper atmosphere, causing strong coupling in a large range of altitudes and latitudes ${ }^{(4,5)}$. Figure 1 depicts the schematic showing the impacts of SSW in a global perspective. As is clear from the figure, associated with SSW, cooling has been reported over polar mesosphere, could be due to the overall atmospheric upwelling effects. This may result in warming over the equatorial mesospheric altitudes owing to the circulation. This can further change the tidal activity over equatorial/low latitude dynamo region and can influence the large scale ionospheric phenomena like Equatorial Electrojet (EEJ), Equatorial Ionization Anomaly (EIA), and Equatorial Spread-F (ESF) etc. Over equatorial thermosphere, associated with SSW, both heating and cooling has been noticed, and it remains one of the open questions to be addressed.

\subsection{Effects of SSW over Troposphere and Stratosphere}

Many of the earlier studies ${ }^{(6,7)}$ have shown that there is a distinct tropospheric response to the SSW induced effects. Although most of the studies were focused on the high latitudes, a few studies have shown that the SSW do have impacts over lowlatitude/tropical troposphere also. ${ }^{(5)}$. Experimental data indicate that there is a significant cooling over low-latitude upper troposphere associated with the SSW ${ }^{(8)}$. Similarly, a cooling in the stratosphere over the equatorial summer hemisphere in association with the SSW has been discussed by ${ }^{(9)}$. The meridional circulation associated with the SSW can induce upwelling in the equatorial region and produce cooling in the equatorial lower stratosphere while modifying the distribution of minor constituents ${ }^{(10)}$.

Besides, many studies have shown that SSW influences the size and intensity of the ozone hole over both Arctic and Antarctic regions substantially, despite its occurrence being significantly smaller in the Antarctic (South Pole) as compared to the Arctic (North Pole) region ${ }^{(11)}$. It is now understood that the descents of wind and temperature anomalies associated with SSW continue to propagate downward on time scales of several weeks, and the impact of SSW on the circulation of troposphere can also last for many weeks ${ }^{(12)}$. Recently tropical connection of SSW has been brought out using the National Centers for Environmental Prediction (NCEP) and the National Center for Atmospheric Research (NCAR) reanalysis data of stratospheric wind and temperature ${ }^{(13)}$. The study showed that there do exist a zero wind line over tropics (where zonal wind amplitude is zero), which act as the critical layer for the propagation of QSPW about 60 days prior to major SSWs. Interestingly it was seen that this zero wind line moves toward pole from equator within this 60 days providing a pathway to the quasi 16 day wave, ensuring pre-conditioning effects of SSW over the topical stratosphere corroborating the past studies ${ }^{(14)}$. Recent studies revealed the role of stratospheric ozone too in modulating the ionospheric electrodynamics during SSW period ${ }^{(15)}$.

\subsection{Effects of SSW over Mesosphere and Thermosphere}

In the mesosphere/thermosphere also, large variability, both experimental and theoretical, had been reported associated with the SSW events. In general, studies have shown that SSW is accompanied by cooling over polar ${ }^{(1)}$ mesosphere. This cooling is attributed to the large dynamical changes associated with the SSW such as reversal of prevailing (zonal and meridional) winds, enhanced energy dissipation rates, increased planetary wave activity and the changes in the gravity wave activity ${ }^{(6)}$. In addition to this, other dynamical changes such as extension of polar vortex into the mesosphere ${ }^{(16)}$, displacement of the temperature maxima at stratopause to $80 \mathrm{~km}^{(17)}$, movement of centroid of $\mathrm{OH}$ emission to lower altitudes due to enhanced downward transport ${ }^{(18)}$ etc. has been reported in conjunction with the SSW. These unusual changes has been ascribed to increase or decrease in the semidiurnal tidal amplitudes/phases and enhanced planetary and gravity wave forcing $(4,16)$

Despite the fact that the strength of SSW associated effects is expected to decrease with latitude, it has been observed that the equatorial mesosphere also exhibits substantial variability in context of SSW. In a study ${ }^{(13)}$, a pre conditioning in the dynamics over tropics much prior to the SSW ( 60 days) has been reported over equatorial mesopause altitudes. Although the polar mesospheric cooling has been confirmed by a number of studies using both Nimbus satellite data $(10 \mathrm{~K}$ at $\sim 80 \mathrm{~km})$, SABER data, Lidar/ OH airglow measurements ( $25 \mathrm{~K}$ in the MLTI region) ${ }^{(15,16)}$, the tropical/equatorial mesospheric response is not properly understood so far. In addition to these, over tropics enhanced gravity wave perturbations associated with SSW ${ }^{(19)}$ have been reported similar to those from high latitudes.

The first observational evidence for the effects of SSW at thermospheric altitudes was reported over mid-latitudes in ${ }^{(20)}$. They showed that there exist alternating regions of warming $(\sim 50 \mathrm{~K})$ in the lower thermosphere $(120-140 \mathrm{~km})$ and cooling $(\sim 70 \mathrm{~K})$ in the upper thermosphere (above $150 \mathrm{~km}$ ) over Millstone Hill ISR $\left(42.6^{\circ} \mathrm{N}\right)$, Although the observations at lower thermosphere are consistent with the modeling predictions ${ }^{(14)}$, the upper thermospheric observations are totally unexpected in any of the simulation studies ${ }^{(20)}$. However, a recent analysis of zonal temperature structure during SSW showed that either warming or cooling can be expected due to the presence of wave 1 pattern in the lower thermosphere. In fact, ${ }^{(21)}$ using simultaneous 
observations from Challenging Minisatellite Payload (CHAMP) and Gravity Recovery and Climate Experiment (GRACE) satellite data showed that the thermospheric density in both the pre-dawn and afternoon local time sectors undergoes significant decrease across both hemispheres during the major stratospheric sudden warming (SSW) in January 2009. The decrease was found to be the largest in the equatorial region near the sub solar latitude, reaching $\sim 30 \%$ at $325 \mathrm{~km}$, and $45 \%$ at $475 \mathrm{~km}$ altitude in the afternoon sector. Further, the data demonstrated the strongest cooling over equatorial latitudes $(\sim 50 \mathrm{~K})$ with a clear-cut longitudinal variability in terms of magnitude and the timing of the maximum cooling. In another study ${ }^{(21)}$ suggested that, it is not possible to ascertain if cooling or warming occurred in the upper thermosphere in response to the stratospheric warming of 2009. This conclusion has arrived after the detailed analysis of the event using three independent models: the NRLMSISE-00 empirical model; the physics-based coupled thermosphere, ionosphere, plasmasphere, and electrodynamics model (CTIPe); the whole atmosphere model (WAM) and CHAMP data. The study also revealed that there is no change in thermospheric mass density/temperature and small changes observed can be attributed to the geomagnetic activity during that period. Nonetheless, the WAM simulation predicted a substantial increase in the amplitude of the 8 hour terdiurnal tide in the lower thermosphere dynamo region in response to the warming, at the expense of the more typical semidiurnal tides suggesting a significant impact on the diurnal variation of the electrodynamics at low latitudes, which further corroborated the observed SSW associated features at equatorial/low latitudes around the globe.

\section{3 lonospheric effects during SSW}

A significant number of studies had been reported from the equatorial/low latitude ionosphere/thermosphere to investigate the SSW induced effects. The following section reviews some of the recent advances made to investigate the SSW induced effects over low latitude/equatorial $\mathrm{E}$ and $\mathrm{F}$ region altitudes.

\subsection{Effects of SSW over lonospheric E region}

As mentioned earlier, a few decades back itself, some of the studies had conjectured the effects of SSW over E region of equatorial/low latitude ionosphere ${ }^{(22)}$. Following this, a number of studies have been carried out to investigate the effects of SSW and E region of the ionosphere ${ }^{(4,13)}$. The occurrence of CEJs using ground based magnetometers, associated with SSW has been reported in a number of studies over Indian and Peruvian longitudinal sectors ${ }^{(4,23)}$. The regular occurrence of CEJs with a quasi 16-day periodicity has been reported recently, during the northern hemisphere mid winter SSW events ${ }^{(24)}$. They found that the strength of the CEJ is directly proportional to the intensity of the SSW events. In addition to this, the quasi 16-day wave was found to modulate the tidal components and the CEJ was found to occur when the amplitude of the tidal components minimizes.

\subsection{Effects of SSW over Ionospheric F region}

Although the past studies have revealed that low latitude E region undergoes significant changes associated with the SSW, its effects over F region are brought out only in recent days. The global spatial (latitude and altitude) structure of the mean ionospheric response to sudden stratospheric warming (SSW) events in winters of 2007/2008 and 2008/2009 was elucidated using COSMIC data of peak value of F2 region electron density (NmF2), height maximum of peak in the electron density $(\mathrm{hmF} 2)$ and electron density at different altitudes ${ }^{(25)}$. The study illustrated a regular negative response in the mean behavior of all these parameters to the SSW temperature pulses. They proposed that the SSW induced strong increase in lower thermospheric temperature can create a situation equivalent to the 'Disturbed Dynamo' action. Due to this strong heating, an equatorward wind will be generated, which will gain a westward flow in the $\mathrm{NH}$ (for the conservation of angular momentum) resulting in 'wind surge' at low and mid-latitudes. As a consequence, this wind surge has to have a significant zonal (westward) component affecting the daily mean vertical plasma drift. This has to become predominantly negative or less positive, pushing the plasma to regions of increased chemical recombination (lower altitudes), ultimately resulting in a negative response to the mean ionospheric behavior.

In this context, it must be mentioned that the vertical $\mathbf{E} \times \mathbf{B}$ drift measurements have brought out significant understanding regarding the effects of SSW over low and equatorial latitudes. ${ }^{(26)}$ noticed some peculiar behavior of vertical $\mathbf{E} \times \mathbf{B}$ drift measurements during January 2008 period using ISR. Their observation revealed that (i) there was a clear-cut signature of a semidiurnal wave with amplitudes much larger (more than 2 times) than the usual standard deviation (ii) the same pattern repeated for few more days and (iii) the drift difference was the largest around sunrise.

Nevertheless, it must be mentioned that some of the studies have revealed the possibility of terdiurnal tides in modulating all the changes occurring in the low-latitude/equatorial ionospheric effects. In this context, an attempt is made here to understand 
the effects of tidal activity, by considering the case of 2008 SSW event. This event has been chosen, as it belongs to low solar activity, where the imprints of direct solar forcing or geomagnetic storm effects are expected to be the minimum. Therefore, most of the observed effects can be attributed to the SSW.

\section{The role of tides in modulating the SSW induced effects}

Figure 2 shows the variation of polar stratosphere temperature (PST) for the period December 2007-January 2008 along with the solar flux and geomagnetic variability. The geomagnetic activity during the period is indicated by the day-to-day variability of the Ap index shown in the top panel. As evident from Figure, the SSW occurred on day number 56 (January 24). Even though the SSW of January 2008 is minor warming (since there is no reversal of zonal wind), it is one of the strongest recorded events in terms of the enhancement in Polar Stratospheric Temperature (PST) ${ }^{(27,28)}$. As is obvious in Figure 2 , the zonal mean zonal wind at $10 \mathrm{hPa}$ do not show any reversal associated with SSW, albeit there is a small decrease at around day number 50. In one of the earlier studies ${ }^{(4)}$ it was observed that the entire equatorial ionosphere, extending right from $\mathrm{E}$ to $\mathrm{F}$ region has responded definitively to the observed effects. They have attributed the effects to the modification of semi-diurnal tides and associated non-linear interaction of wave-tidal activity. However, in one of the earlier simulation studies ${ }^{(29)}$, it was shown that there can be modifications in the semi-diurnal as well as terdiurnal tidal activity associated with SSW. They have clearly shown that the increase in the terdiurnal tide has a clear-cut correlation with SSW. Therefore, in order to delineate the role of exact nature of tidal forcing, we have carried out a detailed analysis, as described below.
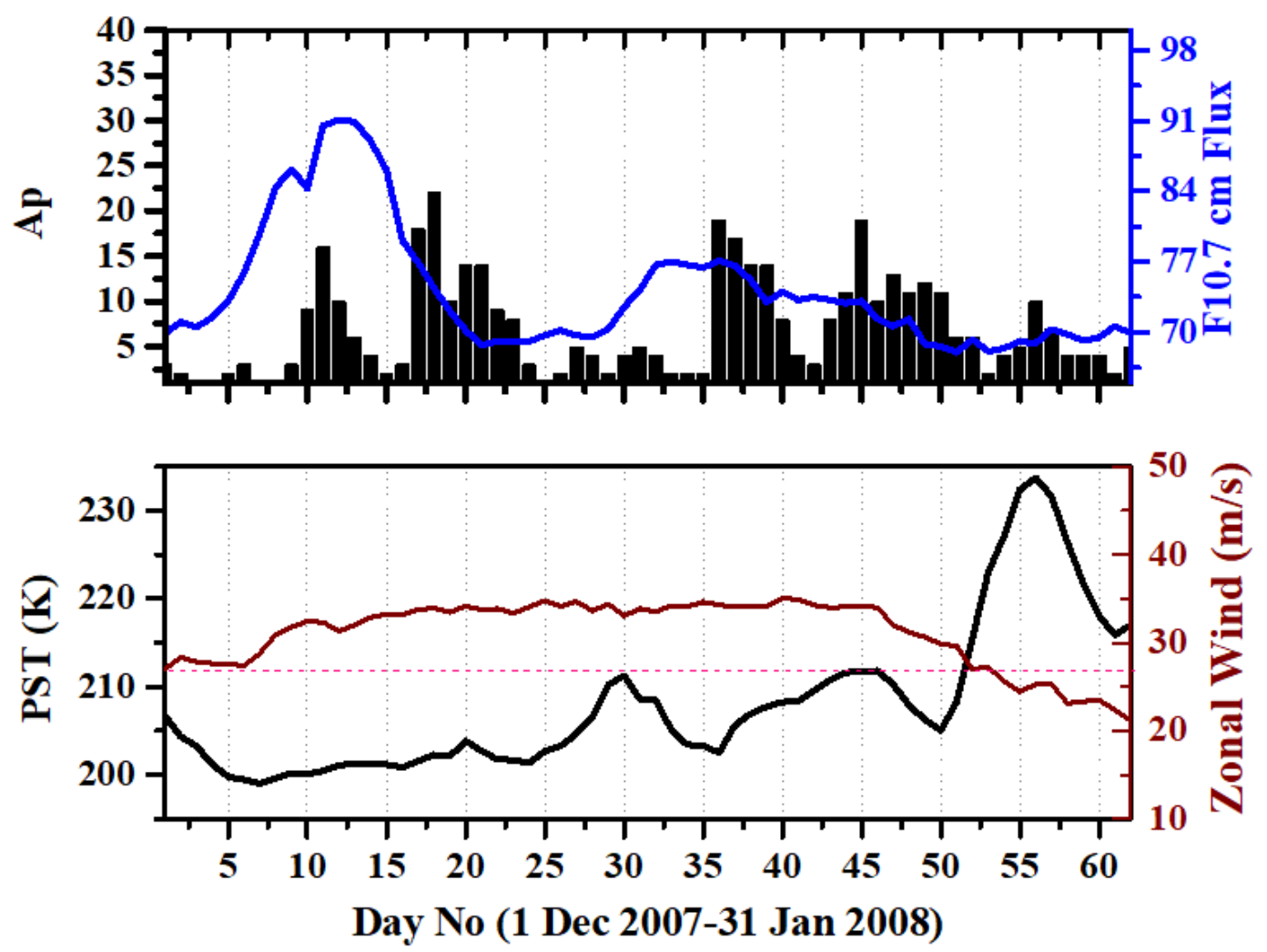

Fig 2. (i) Solar and geomagnetic variability during the SSW event of January 2008 characterized by Solar Flux (F10.7 cm) and Ap index during Dec 2007-Jan 2008 along with (ii) the Polar Stratospheric Temperature (PST) at $10 \mathrm{hPa}$ during the same period The zonal mean zonal wind is also plotted to show that there is no wind reversal associated with this SSW event.

As mentioned above, we have used the zonal wind at different altitudes (82-98 km at an interval of $4 \mathrm{~km}$ ) obtained from the meteor wind radar installed over Trivandrum. For the present analysis, hourly averaged wind data at various altitudes during the period December 2007-January 2008 has been used.

The radar transmits at a peak power of $40 \mathrm{~kW}$ with an operating frequency of $35.25 \mathrm{MHz}$ in pulsed mode to detect meteor trail echoes. It utilizes a transmitter antenna and five separate receiving antennae for the reception of the signal. The signals are then 
multiplexed to a single receiver, in-phase and quadrature components are digitized, and by comparing the phases of the received signals, meteor trail locations can be found to an accuracy of $\pm 1-2^{\circ}$. Once, the meteor trails enter into earth's atmosphere, they first expand laterally by molecular diffusion processes and later by turbulent processes aided by the background neutral winds. The typical life time of these trails vary from a few tenths of a second to few seconds. Tracking these ionization trails will give information about the direction and velocity of background neutral wind using complex auto-correlation and cross-correlation techniques. The details of this radar and estimation technique have been published elsewhere ${ }^{(30)}$.

The amplitudes of semidiurnal and terdiurnal tides have been obtained by using the Morlet wavelet analysis ${ }^{(31)}$. Figure 3 shows the daily variation of semi diurnal and terdiurnal tidal amplitudes derived using the meteor wind radar data. Different symbols are for different altitudes. Top panel is for the month of December 2007 (control period) and bottom panel is for the SSW period (January 2008). It can be seen that a conspicuous increase in the tidal amplitudes is present during the SSW period, especially after 20 January 2008, the peak in PST being on 24 January 2008. It is worthwhile to mention here that the semi diurnal tidal amplitudes are found to be much stronger at higher altitudes than lower altitudes. However, the terdiurnal components did not show any appreciable changes during the SSW period as compared with the control period. The amplification of semi diurnal tidal amplitudes clearly indicates the effect of SSW on the winds in the upper atmosphere. So it can be conclusively stated that it is the semi-diurnal tides, not the terdiurnal tides, whose amplitudes are getting strengthened during the SSW period.
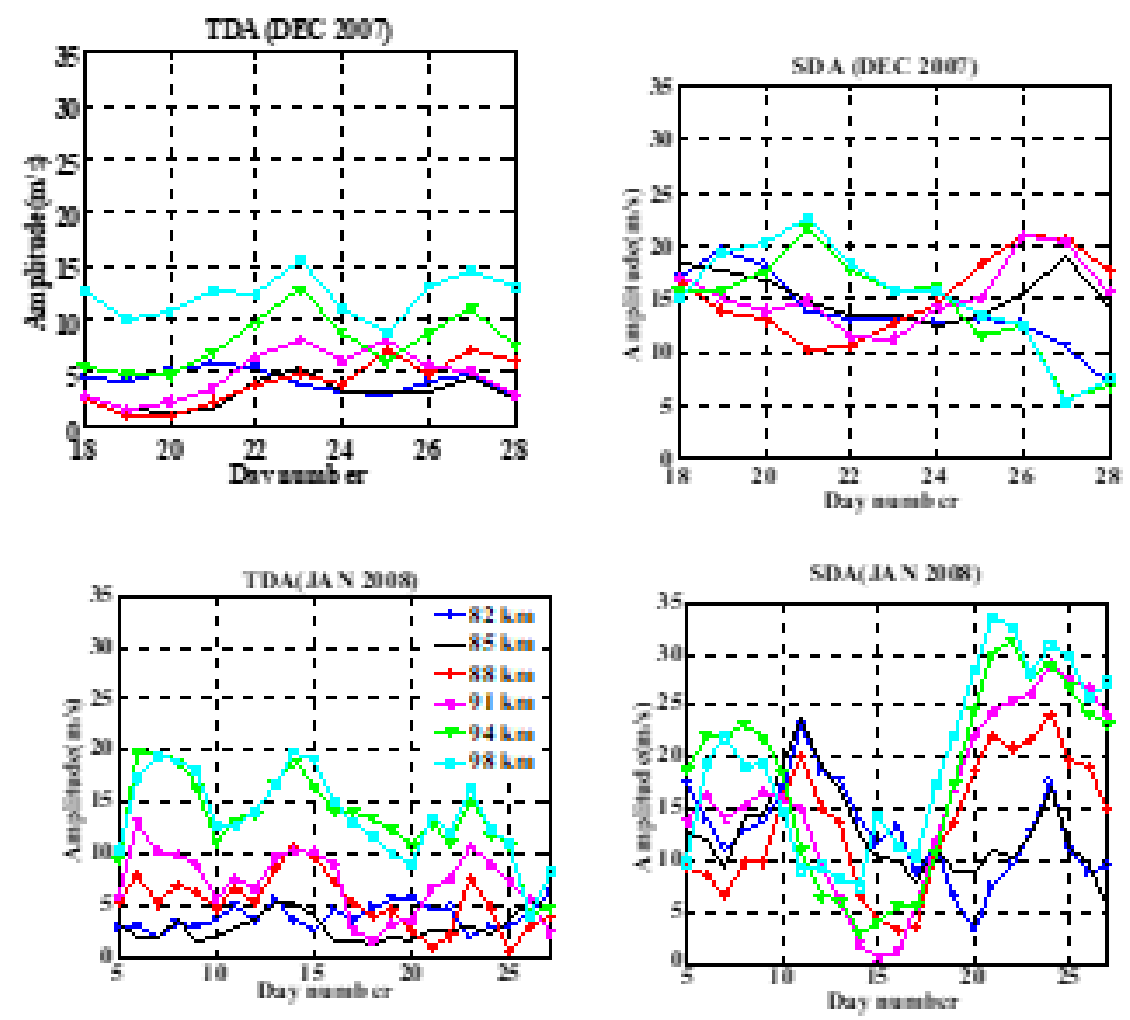

Fig 3. The amplitudes of Terdiurnal (TDA) and Semi-diurnal (SDA) tides during the SSW event of January 2008. A clear-cut enhancement in the SDA is noted associated with peak value of PST

\section{Conclusion}

In the present paper, we have reviewed some of the important scientific results concerning the effects of SSW over the equatorial upper atmosphere $980-500 \mathrm{~km}$ ). An attempt is also made to understand the exact nature of the tidal forcing during the SSW event of January 2008. The zonal wind data at different altitudes (82-98 km at an interval of $4 \mathrm{~km})$ as obtained using a meteor wind radar over a tropical station, Trivandrum in India $\left(8.5^{\circ} \mathrm{N}, 77.0^{\circ} \mathrm{E}\right)$ has been analyzed using the wavelet technique to extract the semi diurnal and diurnal tidal amplitudes during the period. The tidal amplitudes in comparison with the normal period (December 2007) revealed that, there is a distinct enhancement of $\sim 10-15 \mathrm{~m} / \mathrm{s}$ in the semi diurnal tidal activity during the 
SSW period, rather than the terdiurnal forcing. Thus the study provides substantial evidence to one of the hitherto unanswered questions concerning the physical mechanism of the SSW induced effects over the equatorial upper atmosphere. Although we arrived the conclusion after analyzing only one event, i.e., SSW event of January 2008, we believe that it has significant implications in the understanding of SSW induced effects over equatorial upper atmosphere. Analysis using multitude of database from both ground and satellite based platforms are called for in order to have a comprehensive understanding of the cause and effect relationship between the SSW and its ramifications over the equatorial upper atmosphere.

\section{References}

1) Matsuno T. A Dynamical Model of the Stratospheric Sudden Warming. Journal of the Atmospheric Sciences. 1971;28(8):1479-1494. Available from: https://dx.doi.org/10.1175/1520-0469(1971)028<1479:admots >2.0.co;2.

2) Plumb RA. Instability of the Distorted Polar Night Vortex: A Theory of Stratospheric Warmings. Journal of the Atmospheric Sciences. 1981;38(11):25142531. Available from: https://dx.doi.org/10.1175/1520-0469(1981)038<2514:iotdpn>2.0.co;2.

3) Matthewman NJ, Esler JG, Charlton-Perez AJ, Polvani LM. A New Look at Stratospheric Sudden Warmings. Part III: Polar Vortex Evolution and Vertical Structure. Journal of Climate. 2009;22(6):1566-1585. Available from: https://dx.doi.org/10.1175/2008jcli2365.1.

4) Sumod SG, Pant TK, Jose L, Hossain MM, Kumar KK. Signatures of Sudden Stratospheric Warming on the Equatorial Ionosphere-Thermosphere System. Planetary and Space Science. 2012;63(64):49-55. Available from: https://dx.doi.org/10.1016/j.pss.2011.08.005.

5) Pancheva D, Mukhtarov P, Mitchell NJ, Merzlyakov E, Smith AK, Andonov B, et al. Planetary Wave Coupling of the Stratosphere and Mesosphere during the Major Stratospheric Warming. Journal of Geophysical Research. 2003;113:D12105. doi:10.1029/2007JD009011.

6) Thompson DWJ, Baldwin MP, Wallace JM. Stratospheric Connection to Northern Hemisphere Wintertime Weather: Implications for Prediction. Journal of Climate. 2002;15(12):1421-1428. Available from: https://dx.doi.org/10.1175/1520-0442(2002)015<1421:sctnhw>2.0.co;2.

7) Charlton AJ, Polvani LM. A New Look at Stratospheric Sudden Warmings. Part I: Climatology and Modeling Benchmarks. Journal of Climate. 2007;20(3):449-469. Available from: https://dx.doi.org/10.1175/jcli3996.1.

8) Mukhtarov P, Pancheva D, Andonov B, Mitchell NJ, Merzlyakov E, Singer W, et al. Large-scale thermodynamics of the stratosphere and mesosphere during the major stratosphericwarming in. Journal of Atmospheric and Solar Terrestrial Physics. 2003;69(17-18):2338-2354. Available from: https: //doi.org/10.1016/j.jastp.2007.07.012.

9) Dunkerton T, Hsu CPF, McIntyre ME. Some Eulerian and Lagrangian Diagnostics for a Model Stratospheric Warming. Journal of the Atmospheric Sciences. 1981;38(4):819-844. Available from: https://dx.doi.org/10.1175/1520-0469(1981)038<0819:sealdf $>2.0 . c 0 ; 2$.

10) Randel WJ, Garcia RR, Wu F. Time dependent upwelling in the tropical lower stratosphere estimated from the zonal mean momentum budget. Journal of the Atmospheric Sciences. 2002;59(13):2141-2152. Available from: https://doi.org/10.1175/1520-0469(2002)059<2141:TDUITT>2.0.CO;2.

11) Varotsos C. What is the lesson from the unprecedented event over antarctica in 2002. Environmental Science and Pollution Research. 2003;10:80-81. Available from: https://dx.doi.org/10.1007/bf02980093.

12) Polvani LM, Waugh DW. Upward wave activity flux as precursor to extreme stratospheric events and subsequent weather regimes. Journal of Climate. 2004;17(18):3548-3554. Available from: https://doi.org/10.1175/1520-0442(2004)017<3548:UWAFAA>2.0.CO;2.

13) Vineeth C, Pant TK, Kumar KK, Sumod SG. Tropical connection to the polar stratospheric sudden warming through quasi 16-day planetary wave. Annales Geophysicae. 2010;28(11):2007-2013. Available from: https://dx.doi.org/10.5194/angeo-28-2007-2010.

14) Liu HL, Roble RG. Dynamical coupling of the stratosphere and mesosphere in the 2002 Southern Hemisphere major stratospheric sudden warming. Geophysical Research Letters. 2005;32:L13804. doi:10.1029/2005GL022939.

15) Goncharenko LP, Chau JL, Liu HL, Coster AJ. Unexpected connections between the stratosphere and ionosphere. Geophysical Research Letters. 2010;37(10):1-6. Available from: https://dx.doi.org/10.1029/2010gl043125.

16) Siskind DE, Eckermann SD, Coy L, McCormack JP, Randall CE. On recent interannual variability of the Arctic winter mesosphere: Implications for tracer descent. Geophysical Research Letters. 2007;34(9):L09806. Available from: https://dx.doi.org/10.1029/2007gl029293.

17) Manney GL, Schwartz MJ, Krüger K, Santee ML, Pawson S, Lee JN, et al. Aura Microwave Limb Sounder observations of dynamics and transport during the record-breaking 2009 Arctic stratospheric major warming. Geophysical Research Letters. 2009;36(12):L12815. Available from: https://dx.doi.org/10. $1029 / 2009 \mathrm{gl038586.}$

18) Winick JR, Wintersteiner PP, Picard RH, Esplin D, Mlynczak MG, III JMR, et al. OH layer characteristics during unusual boreal winters of. Journal of Geophysical Research. 2009;114(A2):1-9. Available from: https://doi.org/10.1029/2008JA013688.

19) Sathishkumar $\mathrm{S}$, Sridharan S. Planetary and gravity waves in the mesosphere and lower thermosphere region over Tirunelveli $\left(8.7^{\circ} \mathrm{N}, 77.8^{\circ} \mathrm{E}\right)$ during stratospheric warming events. Geophysical Research Letters. 2009;36(7):1-5. Available from: https://dx.doi.org/10.1029/2008gl037081.

20) Goncharenko L, Zhang SR. Ionospheric signatures of sudden stratospheric warming: Ion temperature at middle latitude. Geophysical Research Letters. 2008;35(21):1-4. Available from: https://dx.doi.org/10.1029/2008gl035684. doi:10.1029/2008gl035684.

21) Fuller-Rowell T, Akmaev R, Wu F, Fedrizzi M, Viereck RA, Wang H. Did the January 2009 sudden stratospheric warming cool or warm the thermosphere? Geophysical Research Letters. 2009;38(18):1-6. Available from: https://doi.org/10.1029/2011GL048985.

22) Stening RJ. Electron density profile changes associated with the equatorial electrojet. Journal of Atmospheric and Terrestrial Physics. 1977;39(2):157-164. Available from: https://dx.doi.org/10.1016/0021-9169(77)90109-x.

23) Fejer BG, Olson ME, Chau JL, Stolle C, Lühr H, Goncharenko LP, et al. Lunar-dependent equatorial ionospheric electrodynamic effects during sudden stratospheric warmings. Journal of Geophysical Research: Space Physics. 2010;115(A8):1-9. Available from: https://dx.doi.org/10.1029/2010ja015273.

24) Vineeth C, Pant TK, Devasia CV, Sridharan R. Atmosphere-Ionosphere coupling observed over the dip equatorial MLTI region through the quasi 16-day wave. Geophysical Research Letters. 2007;34(12):1-5. Available from: https://dx.doi.org/10.1029/2007gl030010.

25) Pancheva D, Mukhtarov P. Stratospheric warmings: The atmosphere-ionosphere coupling paradigm. Journal of Atmospheric and Solar-Terrestrial Physics. 2011;73(13):1697-1702. Available from: https://dx.doi.org/10.1016/j.jastp.2011.03.006.

26) Chau JL, Fejer BG, Goncharenko LP. Quiet variability of equatorialE $\times$ Bdrifts during a sudden stratospheric warming event. Geophysical Research Letters. 2009;36(5):5101-5101. Available from: https://dx.doi.org/10.1029/2008g1036785.

27) Kakoti G, Kalita BR, Bhuyan PK, Baruah S, Wang K. Longitudinal and Interhemispheric Ionospheric Response to 2009 and 2013 SSW Events in the African-European and Indian-East Asian Sectors. Journal of Geophysical Research: Space Physics. 2020;125(11):1-11. Available from: https://dx.doi.org/ 
10.1029/2020ja028570.

28) Kozubek M, Lastovicka J, Krizan P. Comparison of Key Characteristics of Remarkable SSW Events in the Southern and Northern Hemisphere. Atmosphere. 2020;11(10):1063-1063. Available from: https://dx.doi.org/10.3390/atmos11101063.

29) Fuller-Rowell T, Wu F, Akmaev R, Fang TW, Araujo-Pradere E. A whole atmosphere model simulation of the impact of a sudden stratospheric warming on thermosphere dynamics and electrodynamics. Journal of Geophysical Research. 2010;115(A10):1-13. Available from: https://doi.org/10. 1029/2010JA015524.

30) Antonita M, Ramkumar G, Kumar KK, Deepa V. Meteor radar observations of gravity wave momentum fluxes in the MLT region and their contribution towards. Mesospheric Semiannual Oscillation Journal of Geophysical Research. 2008;113:1-12. Available from: https://doi.org/10.1029/2007JD009089.

31) Torrence C, Compo GP. A Practical Guide to Wavelet Analysis. Bulletin of the American Meteorological Society. 1998;79(1):61-78. Available from: https://dx.doi.org/10.1175/1520-0477(1998)079<0061:apgtwa>2.0.co;2. 